\title{
Remember me
}

\section{Jane Maienschein}

If I Am To Be Remembered: The Life and Work of Julian Huxley with Selected Correspondence. By K. R. Dronamraju. World Scientific: 1993. Pp. 294. £27, \$38. Julian Huxley: Biologist and Statesman of Science. Edited by C. Kenneth Waters and Albert Van Helden. Rice University Press: 1993. Pp. 344. \$32.50.

IF Krishna Dronamraju's If I am to be Remembered had appeared earlier, we might have been able to say "Well, it's about time that someone took Julian Huxley seriously". Unfortunately for Dronamraju, Waters and van Helden's excellent edited volume appeared at about the same time and has made Dronamraju's much lesser contribution superfluous.

Huxley wrote in his Memories (1970): "If I am to be remembered, I hope it will not be primarily for my specialized scientific work, but as a generalist." Dronamraju quotes Huxley on the first page of his introduction, and then goes on to say that the primary scope of his book is Huxley's biological work. Alas, this is typical of his volume. The focus is not clear-Dronamraju actually offers relatively little about this biological scienceand the discussion is not very rigorous. Instead he offers a somewhat arbitrary collection of prefaces, a weak, repetitious biographical sketch that lacks many clear dates or any sense of context, and a rather jumbled selection of letters from the Huxley

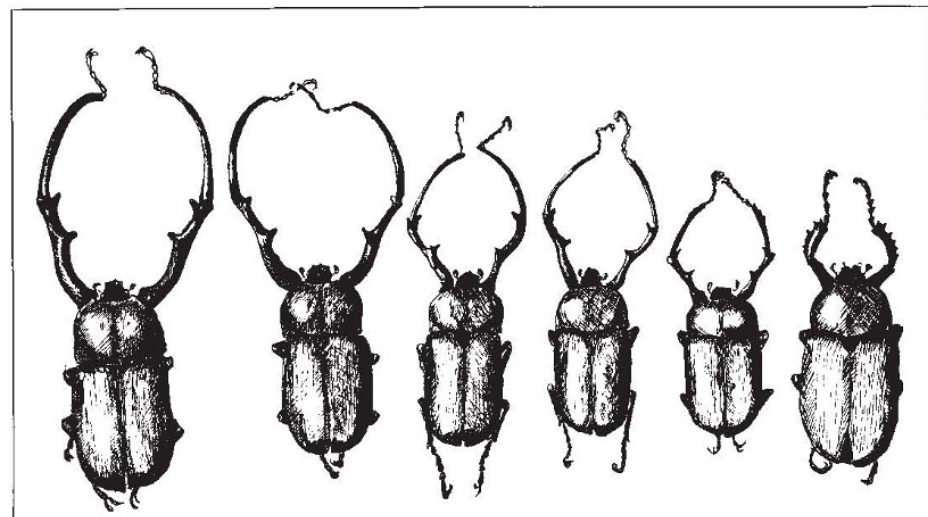

BEETLEMANIA - heterogeny of the male forelimb of the beetle Euchirus longimanus. The specimen on the right is a female, the rest are males of increasing absolute size. From Problems of Relative Growth by Julian Huxley, first published in 1932 and now reprinted. Johns Hopkins University Press, £16.50.
Archives at Rice Universi-

ty. In short, this is a disappointing offering. It is especialy disappointing because Dronamraju evidently attended the conference at Rice that Waters and van Helden organized and that forms the basis for their work. Dronamraju should thus have known that a more serious scholarly historical study on Huxley was in preparation, but he does not mention the conference or its resulting book.

That book, Julian Huxley: Biologist and Statesman of Science, inspires some of the normal reactions to edited efforts: it is uneven, some of the short commentaries add little and could better have been omitted, whereas others are nice additions; a few of the papers seem to have been written for some other purpose and give a nod to Huxley only as an afterthought. Yet, overall, the volume provides a useful and persuasive introduction to this twentieth-century biologist who identified the "modern synthesis" in evo- lutionary biology and who had a hand in many other ventures both public and private. Along the way, some of the contributions are first rate and challenge us to explore further, enticing us to study the rich archival collection kept at Rice University.

What draws the volume together as a whole is Waters' perceptive introductory essay. He provides a biographical sketch that frames the other studies and allows them to probe more substantively into the content of Huxley's historical, biological

another" (Olby).

Jan Witkowski, Frederick Churchill and Richard Burkhardt provide stimulating analyses of Huxley's considerable biological contributions. Witkowski explains Huxley's embryological and cell study in a way that makes it seem perfectly reasonable that an intelligent Huxley of the early twentieth century should be attracted to such research problems as the study of cell (de)differentiation and relative growth. Where Dronamraju asserts that some of this work was Huxley's best but does not explain it very well or make it clear just what the contribution was, Witkowski does both. Churchill's perceptive essay furthers the discussions by showing how Huxley sought to combine the organismic gradient interpretation of Charles Manning Child with Hans Spemann's somewhat antithetical organizer theory. Churchill argues that Huxley embraced the "English emphasis on the organism as a dynamic, biochemically integrated whole rather than on the cell as the basic unit of life." Burkhardt then considers another phase of Huxley's biological work, his field study of the natural history of bird behaviour. A total of only 40-50 days (or even partial days) in the field produced useful ethological contributions but not, as Burkhardt argues persuasively, the major synthetic or pioneering work that Huxley later saw himself as having provided.

G. Allen, D. Paul and D. Kevles examine Huxley's popular work in a section entitled "Huxley the Statesman of Science." Allen and Paul interpret Huxley's eugenic views somewhat and public contributions. This excellent overview presents an intriguing portrait of Huxley as a real person, seized by periods of self-doubt alternating with episodes of prodigious enterprise. Huxley emerges neither as the glorious architect of the synthesis, nor as a deflated and somehow disappointingly deficient member of the great Huxley clan. This volume as a whole invites us to look at Huxley - and twentieth-century science along with its social context - in a different and richer way.

Strong essays by Colin Divall and Robert Olby place Huxley in his society, as a humanist who may have been a Victorian thinker trapped in an "unsympathetic modern age" (Divall) or as a complex outsider of whom his wife Juliette said that "[ $t]$ here were, in fact, so many Julians within this tall carelessly dressed wanderer bent on his various ploys, escaping from one activity by diving into yet differently, and the two together offer a rich sense of the reasoning and (implicitly) the role of secular humanism behind this prominent eugenicist's public views.

This volume as a whole provides an introduction to this particular Huxley. Although there is little detailed discussion of his administrative roles at the London Zoo or UNESCO, for example, or of the effects on his science of his nervous breakdowns and insecurities, the collection offers points of contact for such study. And the Rice archives offer a rich starting point, as Nancy Boothe's appendix explains. With Huxley's own two-volume autobiography, the foundation is well laid for the "further research" to which the editors invite readers.

Jane Maienschein is in the Departments of Philosophy and Zoology, Arizona State University, Box 872004, Tempe, Arizona 85287-2004, USA. 